\title{
Correction to: Floral development of petaloid Alismatales as an insight into the origin of the trimerous Bauplan in monocot flowers
}

\author{
Akitoshi Iwamoto $^{1}$ (1) Ayaka Nakamura ${ }^{1}$. Shinichi Kurihara ${ }^{1} \cdot$ Ayumi Otani $^{1} \cdot$ Louis P. Ronse De Craene $^{2}$
}

Published online: 20 April 2018

(c) The Botanical Society of Japan and Springer Japan KK, part of Springer Nature 2018

Correction to: Journal of Plant Research

https://doi.org/10.1007/s10265-018-1022-0

The caption of Fig. 5 was published incorrectly in the original publication of the article. "Egeria densa" should be replaced with "Hydrocharis dubia" in the caption of Fig. 5.

In addition, capitalization was processed incorrectly in the following subtitles of Results as "Floral development of butomus umbellatus" and "Floral development of alisma lanceolatum. The correct subtitles should be "Floral development of Butomus umbellatus" and "Floral development of Alisma lanceolatum".

The original article can be found online at https://doi.org/10.1007/ s10265-018-1022-0.

Akitoshi Iwamoto

akitoshi@u-gakugei.ac.jp

1 Department of Biology, Tokyo Gakugei University, 4-1-1

Nukui Kita-machi, Koganei-shi, Tokyo 184-8501, Japan

2 Royal Botanic Garden Edinburgh, 20A Inverleith Row,

Edinburgh EH3 5LR, UK 